\title{
Diagnosis by ultrasound of severe carotid artery disease in patients undergoing cardiopulmonary bypass operations
}

\author{
R R LEWIS, $M$ G BEASLEY, A AYOUB, $P$ B DEVERALl, A K YATES, \\ R G GOSLING \\ From Guy's Non-Invasive Angiology Research Group, Clinical Science Laboratories, \\ Guy's Tower; and Department of Cardiac Surgery, New Guy's House, Guy's Hospital, London
}

SUMMARY A non-invasive method using continuous wave Doppler shift ultrasound and spectral analysis was used as a screening test for severe carotid artery disease in patients undergoing cardiopulmonary bypass operations. One hundred and eighty-eight patients were examined before cardiac surgery (91 for ischaemic heart disease, 17 for ischaemic heart disease and valve replacement, 66 for valve replacement alone, and 14 for congenital abnormalities). The mean age of the 108 patients suffering from ischaemic heart disease was 54 years $( \pm 8)$ and that of the 80 patients admitted either for valve replacement alone or for congenital abnormalities was 52 years $( \pm 12)$. Five of the 108 patients suffering from ischaemic heart disease were found to have severe occlusive disease of the internal carotid artery by the ultrasound test, while the test was normal in the other two groups. Patients with severe carotid artery disease proceeded to carotid arteriography and endarterectomy before the planned heart operation.

Symptoms of cerebrovascular ischaemia are a wellrecognised complication of open heart operations. ${ }^{1-3}$ One explanation of such symptoms is that during surgery the blood pressure may be lowered on occasions to $40 \mathrm{mmHg}$ or less and if severe occlusive carotid artery disease coexists this results in reduced cerebral perfusion. ${ }^{4}$ This is likely to occur because occlusive arterial disease is often a generalised condition and both carotid and coronary arteries are favoured sites for the deposition of atheroma. The number of patients requiring open heart surgery is increasing, especially for treatment of ischaemic heart disease, and with the improvement in surgical techniques operations on older subjects are now undertaken. ${ }^{256}$ There is, therefore, likely to be an associated increase in the incidence of postoperative complications resulting from carotid artery disease. Before this study was undertaken two patients in our department had recently died after operation without regaining consciousness despite no obvious complications occurring during cardiopulmonary bypass and necropsy showed severe, undiagnosed carotid artery disease in both cases.

Kartchner and $\mathrm{McRae}{ }^{7}$ have reported the value Received for publication 17 October 1979 of oculoplethysmography for preoperative assessment of the carotid arteries in 216 patients undergoing operative procedures involving the heart, abdominal aorta, or arteries of the lower limb. Seventy-two patients were shown to have severe carotid artery disease, 35 of whom proceeded to carotid endarterectomy before the planned procedure and experienced no complications of cerebrovascular ischaemia from either operation. The remaining 37 patients in this group did not have a carotid endarterectomy and seven (19\%) developed symptoms of cerebrovascular ischaemia after the planned operation.

Any non-invasive method used for assessing occlusive disease of the carotid arteries should identify those patients with a lesion severe enough to reduce distal mean pressure in the internal carotid artery. This paper is a report of our experience using Doppler shift ultrasound and spectral analysis ${ }^{8} 9$ for this purpose in patients undergoing open heart surgery.

\section{Subjects and methods}

A total of 188 patients was assessed; 108 (94 men and 14 women) suffered from ischaemic heart 
disease and were admitted for aortocoronary bypass graft operations, and 80 patients (40 men and 40 women) required open heart surgery for valve replacement or congenital abnormalities. The mean age of the first group was 54 years $( \pm 8)$ and that of the other group 52 years $( \pm 12)$. Twenty-three had suffered from transient ischaemic attacks or had a localised carotid bruit, or both, as shown in Table 1.

The Doppler assessment was performed with the patient unsedated and lying supine on a couch. A Parks 805 blood velocimeter $(10 \mathrm{MHz})$ was used to record Doppler shift signals from the supraorbital artery and the carotid bifurcation. This velocimeter was modified by the addition of a phase resolver ${ }^{10}$ to permit simultaneous presentation of blood flowing towards and away from the transducer, thus providing information about the direction of blood flow in the insonated artery even in the presence of interference from venous signals. The transducer was placed on the skin overlying the artery of interest and backscattered signals from erythrocytes were immediately displayed by a spectral analyser ${ }^{8}$ in sonogram form (Fig. 1).

The screening procedure consisted of insonating the supraorbital artery and observing the shape of the sonogram and direction of blood flow, both of which indicate whether disease is present. ${ }^{9}$ The temporal artery occlusion test described by Brockenbrough ${ }^{11}$ was modified!2 and used to detect lesions severe enough to cause a reduction in distal mean pressure in the internal carotid pathway. This test relies on the fact that normally there is equal pressure in the internal carotid and external carotid arteries. These two vessels usually form an anastomotic vascular bed in the region of the forehead via collateral vessels from the supraorbital and superficial temporal arteries, and in the normal situation there is a pressure gradient between the supraorbital artery and this collateral bed such that blood flows out of the orbit. If the pressure in the superficial temporal artery is reduced by digital compression there is a greater pressure gradient

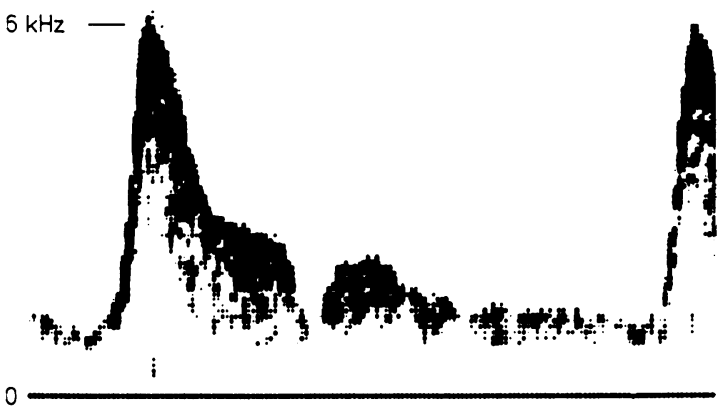

Fig. 1 Normal sonogram from the common carotid artery over one cardiac cycle. Doppler shift frequency is on the $Y$-axis and time is on the $X$-axis. The blackness of the trace at any point is related to the number of erythrocytes generating the same Doppler shift (that is moving at the same velocity).

and erythrocyte velocities increase in the supraorbital artery (Fig. 2). However, if disease is present in the internal carotid artery sufficient to cause a reduction in distal mean pressure, blood flows into the orbit from the superficial temporal artery which is then at a higher pressure than the supraorbital artery. In this situation compression of the superficial temporal artery will usually stop or significantly reduce flow from the external carotid pathway into the supraorbital artery (Fig. 2). The presence of other collateral vessels may cause inaccurate results and we therefore compress other branches of the external carotid arteries both separately and simultaneously; these principally include the ipsilateral facial artery and contralateral superficial temporal and facial arteries.

The carotid bifurcation was then insonated, and when severe disease was present near the origin of the internal carotid artery high-velocity or turbulent Doppler shift signals ${ }^{9}$ were usually obtained. The absence of a signal from the internal carotid artery indicated that this artery was totally occluded.

The presence of severe carotid artery disease shown by the non-invasive investigation was

Table 1 Patients assessed using ultrasound for carotid artery disease before cardiopulmonary bypass surgery

\begin{tabular}{|c|c|c|c|c|c|}
\hline \multirow[b]{2}{*}{ Operation } & \multicolumn{5}{|c|}{ Patients examined } \\
\hline & $\begin{array}{l}\text { No. of } \\
\text { patients }\end{array}$ & $\begin{array}{l}\text { Transient ischaemic } \\
\text { attack }(T I A)\end{array}$ & $\begin{array}{l}\text { Neck bruit } \\
\text { transmitted from } \\
\text { heart }\end{array}$ & $\begin{array}{l}\text { Localised carotid } \\
\text { bruit }(L C B)\end{array}$ & $\begin{array}{l}T I A \\
\text { and } \\
L C B\end{array}$ \\
\hline $\begin{array}{l}\text { Coronary artery bypass graft (CABG) } \\
\text { Valve replacement (VR) } \\
\text { CABG and VR } \\
\text { Congenital abnormality } \\
\text { Total }\end{array}$ & $\begin{array}{r}91 \\
66 \\
17 \\
14 \\
188\end{array}$ & $\begin{array}{r}6 \\
9 \\
1 \\
0 \\
16\end{array}$ & $\begin{array}{r}0 \\
22 \\
7 \\
4 \\
33\end{array}$ & $\begin{array}{l}5 \\
0 \\
2 \\
0 \\
7\end{array}$ & $\begin{array}{l}1 \\
0 \\
1 \\
0 \\
2\end{array}$ \\
\hline
\end{tabular}


confirmed by carotid arteriography and an endarterectomy was performed six to eight weeks before open heart surgery.

\section{Results}

(1) ULTRASOUND SCREENING TEST A summary of the 188 patients in this study is shown in Table 1 , and in Table 2 are details of the five patients found to have severe internal carotid artery disease by the ultrasound examination. A diagnosis of bilateral severe disease was made in case 5, with complete occlusion of the left internal carotid artery.

(2) CAROTID ARTERIOGRAPHY

The ultrasound diagnosis was confirmed by carotid arteriography in four patients (cases 1 to 4). Total

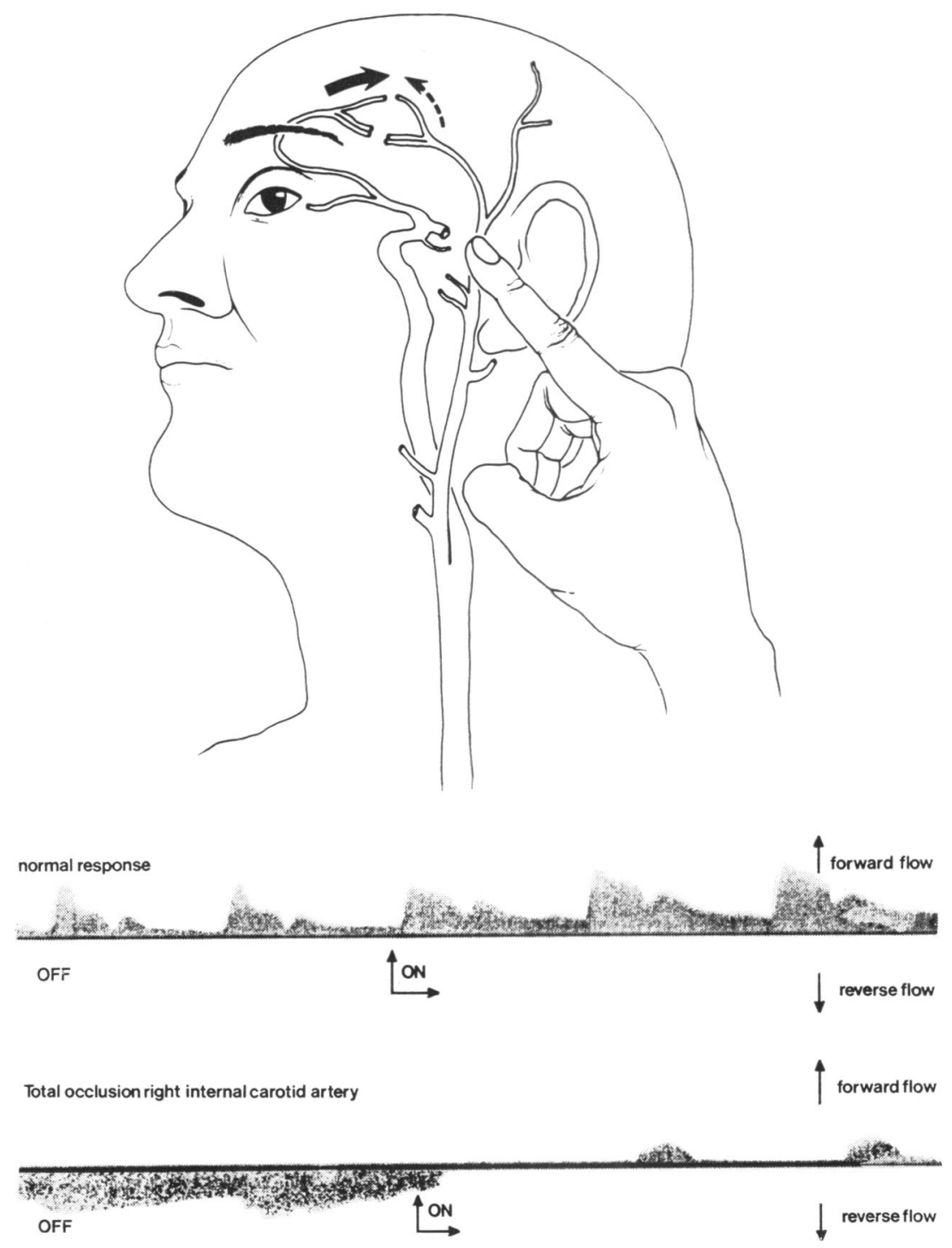

Fig. 2 Above: Diagrammatic illustration of the anastomotic vascular bed between the internal and external carotid arteries in the forehead. The temporal artery occlusion test is performed by insonating the supraorbital artery and compressing the ipsilateral superficial temporal artery against the cranium. Below: Sonograms demonstrating a normal temporal artery occlusion test (top line) with augmentation of flow-velocities during compression. In an abnormal test (bottom line) blood flows initially into the orbit and is stopped by compression. In the case illustrated some blood then flows out of the orbit, indicating additional collateral supply to the internal carotid pathway. 
occlusion of the left internal carotid artery was confirmed in case 5, but on the right side the angiogram showed only minor lesions at both the origin and siphon of the internal carotid artery.

No complications occurred as a result of arteriography.

\section{(3) SURGERY}

Of the five carotid endarterectomies performed in patients shown to have severe disease by the ultrasound technique the only complication was in case 2 who had a left carotid endarterectomy and developed mild weakness of the right arm after the operation.

In case 5 , though the right carotid arteriogram demonstrated only a 14 per cent reduction in lumen diameter, an endarterectomy was performed as the patient had had recent transient ischaemic attacks and the non-invasive investigation indicated that severe disease was present. This disagreement between the ultrasound and arteriogram result could have been partly explained by disease being present at more than one site, but may also have been a result of the $x$-ray image underestimating the size of the lesion at the origin of the internal carotid artery. This proved to be the case as at operation severe disease was found at the carotid bifurcation.

After open heart surgery one of the five patients died without regaining consciousness and necropsy disclosed a recent myocardial infarct. There were no cerebrovascular complications after cardiac surgery in the other patients who had had a carotid endarterectomy.

\section{Discussion}

An interesting finding in this study was that severe carotid artery disease was not found in patients who did not suffer from ischaemic heart disease, though the mean age of this group was similar to that of the group with the ischaemic heart disease. Five per cent of patients suffering from ischaemic heart disease were found to have severe occlusive lesions in the internal carotid artery. This finding accords with other reports that there is an association between the presence of occlusive arterial disease in the coronary and carotid arteries. ${ }^{13} 14$ Though in this study carotid endarterectomy was undertaken some weeks before the heart operation, the two operations have been performed at the same time..$^{15} 16$

This study confirms the limitations of relying on the presence of either a localised bruit in the neck or symptoms of cerebrovascular disease as indicators of severe occlusive disease of the carotid arteries. ${ }^{9}{ }^{17} 18 \mathrm{~A}$ localised bruit was not present in three of the five patients with a severe internal carotid lesion (Table 2). In another patient one internal carotid artery was completely occluded but bilateral carotid bruits were present, and the fifth patient had only minor disease on the side of the bruit but severe disease on the contralateral side. The use of spectral analysis allows the examiner to know in which artery a bruit originates ${ }^{19}$; one patient with ischaemic heart disease who had not suffered from neurological symptoms had a localised carotid bruit and the ultrasound investigation demonstrated disease in the external carotid artery. Two patients with severe lesions in the internal carotid artery suffered from transient ischaemic attacks and only one of these had a carotid bruit associated with these symptoms. However, 14 other patients had also suffered from transient ischaemic attacks, and ultrasound showed no evidence of severe disease. Furthermore, two patients with severe internal carotid artery disease had no signs or symptoms of cerebrovascular disease.

In this study bilateral carotid arteriography was performed, but as confidence increases in the ultrasound diagnosis unilateral arteriography may be sufficient when ultrasound shows the presence of severe disease on one side only. An ultrasound vessel imaging system $^{20}$ is now being used for

Table 2 Details of patients shown by ultrasound to have severe internal carotid disease

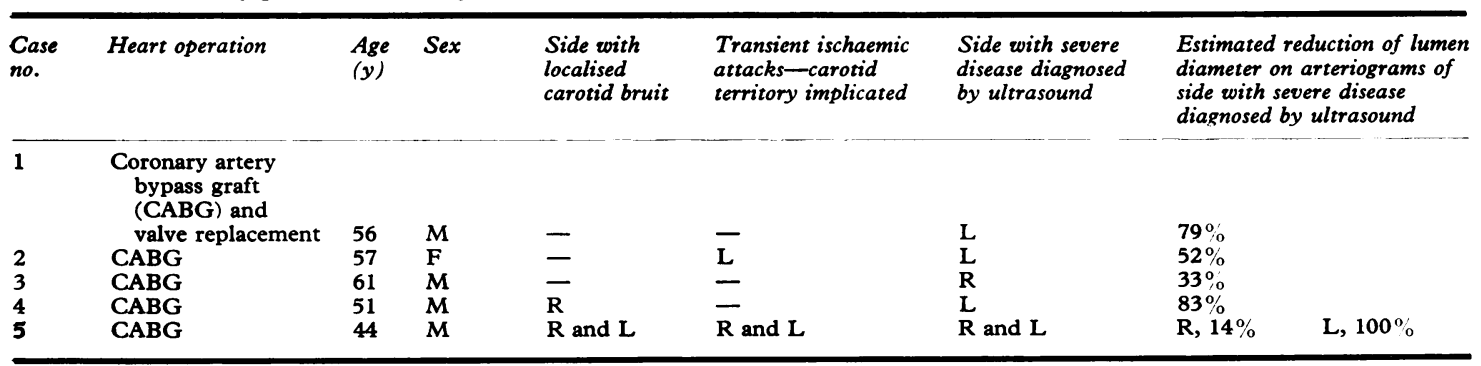


further confirmation of the presence of disease at the carotid birfurcation, so that in cases of total occlusion of the internal carotid artery the noninvasive investigation may obviate the need for arteriography and allow precautions to be taken during open heart surgery.

Non-invasive assessment of the extracranial cerebral arteries using Doppler shift ultrasound and spectral analysis is a safe and relatively easy investigation to perform. It can be performed on an outpatient basis, has no contraindications, and the costs are approximately 10 per cent of those for arteriography. We suggest that this is a valuable preoperative investigation for all patients undergoing open heart surgery for ischaemic heart disease. However, the case for carotid endarterectomy as a treatment for both haemodynamically significant and minor carotid artery disease in these patients has still to be established in further studies.

We thank the British Heart Foundation for its financial support, and the Wellcome Trust, the Medical Research Council, and the Endowments Fund of Guy's Hospital for accompanying support. We acknowledge help from fellow members of Guy's Non-Invasive Angiology Research Group.

\section{References}

${ }^{1}$ Gilman S. Cerebral disorders after open-heart surgery. $N$ Engl f Med 1965; 272: 489-98.

${ }^{2}$ Ashor GW, Meyer BW, Lindesmith GG, Stiles QR, Walker GH, Tucker BL. Coronary artery diseasesurgery in 100 patients 65 years of age and older. Arch Surg 1973; 107: 30-3.

${ }^{3}$ Lawrie GM, Morris GC Jr, Howell JF, et al. Results of coronary bypass more than 5 years after operation in 434 patients. Am $\mathcal{F}$ Cardiol 1977; 40: 665-72.

${ }^{4}$ Ross Russell RW, Bharucha $\mathrm{N}$. The recognition and prevention of border zone cerebral ischaemia during cardiac surgery. $Q \mathcal{F}$ Med 1978; 47: 303-23.

${ }^{5}$ Spencer FC, Trinkle JK, Eiseman B, Reeves JT, Surawicz B. Aortic valve replacement in elderly patients with cardiac failure. $\mathcal{F} A M A 1964$; 189: 103-7. ${ }^{6}$ Guthrie RB, Spellberg RD, Benedict JS, Buhl TL. Open-heart valve surgery in patients 65 and older. Arch Surg 1972; 105: 42-3.

'Kartchner MM, McRae LP. Extracranial carotid occlusive disease as a risk factor in cardiovascular surgery (abstract). Am $\mathcal{F}$ Cardiol 1978; 41 : 410.
${ }^{8}$ Coghlan BA, Taylor MG, King DH. On-line display of Doppler-shift spectra by a new time compression analyser. In: Reneman R, ed. Cardiovascular applications of ultrasound. Amsterdam: North-Holland, 1974: 55-68.

${ }^{9}$ Baskett JJ, Beasley MG, Murphy GJ, Hyams DE, Gosling RG. Screening for carotid junction disease by spectral analysis of Doppler signals. Cardiovasc Res 1977; 11: 147-55.

${ }^{10}$ Coghlan BA, Taylor MG. Directional Doppler techniques for detection of blood velocities. Ultrasound Med Biol 1976; 2: 181-8.

${ }^{11}$ Brockenbrough EC. Screening for the prevention of stroke : use of a Doppler flowmeter. Seattle: Washington/ Alaska Regional Medical Program, 1970.

${ }^{12}$ Bone GE, Barnes RW. Clinical implications of the Doppler cerebrovascular examination: a correlation with angiography. Stroke 1976; 7: 271-274.

${ }^{13}$ De Bakey ME, Crawford ES, Cooley DA, Morris GC $\mathrm{Jr}$, Garret HE, Fields WS. Cerebral arterial insufficiency: one to 11 year results following arterial reconstructive operation. Ann Surg 1965; 161 : 921-45.

${ }^{14}$ DeWeese JA, Rob CH, Satran R, et al. Results of carotid endarterectomies for transient ischemic attacks: five years later. Ann Surg 1973; 178: 258-64.

${ }^{15}$ Bernhard VM, Johnson WD, Peterson JJ. Carotid artery disease: association with surgery for coronary artery disease. Arch Surg 1972; 105: 837-40.

${ }^{16}$ Ennix CL, Lawrie GM, Morris GC, et al. Improved results of carotid endarterectomy in patients with symptomatic coronary disease: an analysis of 1546 consecutive carotid operations. Stroke 1979; 10: 122-5.

${ }^{17}$ Ziegler DK, Zileli T, Dick A, Sebaugh JL. Correlation of bruits over the carotid artery with angiographically demonstrated lesions. Neurology (Minneap) 1971; 21: 860-5.

${ }^{18}$ Kartchner MM, McRae LP, Crain V, Whitaker B. Oculoplethysmography: an adjunct to arteriography in the diagnosis of extracranial carotid occlusive disease. Am $\mathcal{F}$ Surg 1976; 132: 728-32.

${ }^{19}$ Lewis RR, Beasley MG, Gosling RG. Disease at the carotid bifurcation: diagnosis by Doppler ultrasound imaging. Gerontology 1979; 25: 291-8.

${ }^{20}$ Lewis RR, Beasley MG, Hyams DE, Gosling RG. Imaging the carotid bifurcation using continuous wave Doppler-shift ultrasound and spectral analysis. Stroke 1978; 9: 465-71.

Requests for reprints to Dr R R Lewis, Ultrasonic Angiology Unit, Clinical Science Laboratories, Guy's Tower (17th and 18th Floors), Guy's Hospital, London SE1 9RT. 